\title{
Assessment of knowledge on Ill-effects of alcoholism among alcoholic who attend the de-addiction clinics in IGGMGH.
}

*Ms. Jayasri. J \& **Prof.Dr.Babay Rathinasabapathy

\begin{abstract}
:
Objectives: To assess the knowledge on ill-effects of alcoholism among alcoholic. Method: The research design used for this study was Non experimental Descriptive research design. Results: The findings of the study stated that 8 (26.67\%) had inadequate knowledge, 18(63.33\%) moderate knowledge on ill effect of alcoholism and4(10\%) had adequate knowledge. Conclusion: Alcoholism is epidemic and moving towards the poorer and least educated in world wide. At present the incidence of alcoholism is steadily increased. Action must be taken to control the alcoholism. The Psychiatric Nurse must involve in teaching the hazards of alcoholism and about the problem faced by the alcoholic as well as the total family and society.
\end{abstract}

Key words: Alcoholism, Ill- effects

\section{INTRODUCTION}

Drink makes a man forget himself, unable him to distinguish between his wife and sister, loses control over his tongue and other limbs. Alcoholism is recognized as one of the major health problem in India, where numerous factors appear to be interrelated in the development of alcohol dependence, which includes genetic and biological factors, psychological factors, cultural and environment. (Lewis-2004) ${ }^{4}$ The prevalence of alcohol use in India is generally regarded as a traditional "dry" or "abstaining" culture.

About $70 \%$ of HIV and Tuberculosis patients were alcoholic (NIMHANS-2003) and there were 192.18 deaths due to drink and drive accidents (Lamely.T-2003) ${ }^{2}$

\section{NEED FOR THE STUDY}

In 1956, WHO and American Psychiatric Association declared that "Alcoholism is a disease and needed treatment". Alcohol has been one of the most commonly used chemical substances for intoxication by man and cause physical, psychological and social problems. 
A legal harm of excessive alcohol use represent a major public health problem (Anderson et al-1993).The WHO estimated that there are about two million people worldwide consuming alcoholic beverage, in that 76.3 million were diagnosed as alcohol use disorder and causes $3.2 \%$ of deaths and $4 \%$ of disability. Alcohol is the 3rd largest health care problem in India and there is 40 to $50 \%$ increase in the amount of alcohol consumption between 20082010, which increased the number of deaths owing to liver disease(hepatitis and cirrhosis of liver) due to "consistent westernization" said by Dr. Ramamurthy, gastroenterology, Apollo, Chennai (THE HINDU-2010) ${ }^{6}$

Alcohol has been in practice for several years in Pondicherry and approximately $\quad 40.8 \% \quad(3,77,322)$ of people are consuming it .Alcoholism is one of the major cause for suicide i.e. 210 suicides every year and many families of alcoholics were suffering economically ,emotionally, socially, and the children of alcoholic parents are becoming orphans, illiterate and involving in antisocial activities, thus it is a part of health personnel duty to explain the ill effects of alcoholism said by Dr. Dilipkumar, Director of health and family welfare, Pondicherry. (THE HINDU- 2010) ${ }^{6}$

\section{OBJECTIVES}

1. To assess the level of knowledge regarding ill effects of alcoholism among alcoholics.

2. To associate the level of knowledge with selected demographic variables.

\section{HYPOTHESES}

- $\quad$ H1 - There will be significant association in level of knowledge regarding ill effect of alcohol with selected demographic .

\section{METHODOLOGY:}

Quantitative approach is used to assess the level knowledge regarding ill effect of alcohol among alcoholics .The research design used for this study was Non experimental Descriptive research design. The study was conducted in Indira Gandhi Government General Hospital, Puducherry with 30 alcoholic patients who were attending De-addiction clinics in psychiatric OPD They were selected by using Simple random sampling technique. The data was analysed by using descriptive statistics like frequency, percentage, mean, standard deviation.

\section{MAJOR FINDINGS}

\section{Distribution of Socio-demographic Variables}

In demographic variable with regard to the age $12(43.33 \%)$ belonged to the age group of $30-39$ years, 8 (36.67\%) belonged to $40-49$ years, $6(11.67 \%)$ belonged to $20-29$ years and $4(8.33 \%)$ belonged to 50-59 years. Regarding the education status $12(30 \%)$ were graduates, $10(25 \%)$ had middle school education and illiterate, 8 (20\%) got higher secondary education. Regarding the residential area $22(71.20 \%)$ were from Urban area and 8 (28.80\%) were from rural. Regarding marital status18 (88.33\%) were married and $12(11.67 \%)$ were unmarried. 
According to the type of marriage 16 (50\%) had love marriage and $14(40 \%)$ was arranged marriage. Regarding the number of children $18(48.33 \%)$ were having two children, $8(18.33 \%)$ had one child and $4(7 \%)$ have more than two children. Regarding the type of family $22(73.33 \%)$ belongs to nuclear family and $8(26.66 \%)$ belongs to joint family. Regarding the occupational status 18(81.67\%) were employed, $8(11.67 \%)$ were self employed and 4(6.6\%)were unemployed. Regarding the income of the family majority of $16(63.33 \%)$ belonged to income of $3,000-5,000,6(10 \%)$ belonged to income of Rs. $<1500,2(5 \%)$ had an income between Rs.1,500-3000 and 6(21.67\%) had an income of Rs. $>5000$. Regarding the religion 18(65\%) were Hindus, $8(26 \%)$ were Muslims, 4(15\%) were Christians. Regarding dietary pattern $4(13.67 \%)$ were vegetarian and 26(73.33\%) were non vegetarian. Regarding any other habits $12((50 \%)$ were smokers, 8(36.66\%) were consuming coffee and tea, $2(5 \%)$ had habit of tobacco chewing and others $8(8.33 \%)$. Regarding the duration of alcoholic $27(91.6 \%)$ were $<5 y$ rs and $3(8.37 \%)$ were $>5 \mathrm{yrs}$

\section{Distribution of the level knowledge on ill effect of alcoholism among alcoholics}

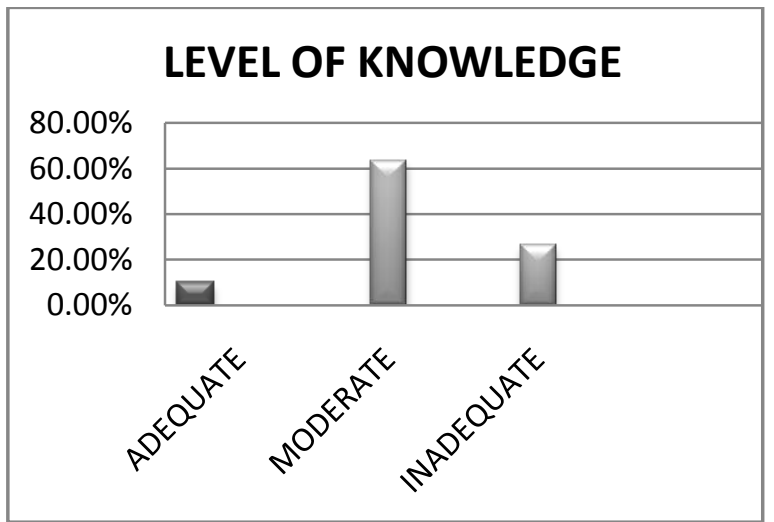

The findings of the study stated that $8(26.67 \%)$ had inadequate knowledge, 18(63.33\%) moderate knowledge in assessment of ill effect of alcoholism and adequate knowledge 4(10\%)

There is no significant association in the level of knowledge with selected demographic variables such as age, education, place of living, marital status, type of marriage, number of children, type of family, occupation, income, religion, dietary pattern, any other personal habits, family history of alcohol consumption, duration of consumption.

\section{CONCLUSION}

Alcoholism is epidemic and moving towards the poorer and least educated in world wide. At present the incidence of alcoholism is steadily increased. Action must be taken to control the alcoholism. The Psychiatric Nurse must involve in teaching the hazards of alcoholism and about the problem faced by the alcoholic as well as the total family and society.

\section{REFERENCES}

1. Abdullah et al. (1979). Better patient care through nursing research. revised edition, Newyark: Millian publishing company. Pp:671.

2. Addiction to alcohol and drug dependency. the professional's master guide. Chennai: T.T. Ranganathan clinical research foundation. Pp:31-63. 
3. Ahiya, N. (2004). A short test book of Psychiatry. 5thed, Medical publisher (P) Ltd. Pp:34-38

4. Alcholism and drug department. the professional's master guide. Chennai: T.T. Ranganathanclinical research foundation. Pp:29-35

5. American medical association. (2005). Alcohol policy, traffic totalities, alcohol accessibility. January 7, 1-5.

6. AnandhiAruna, P. (1989). The reason led to the consumption of alcohol \& the problems experienced by the alcoholics \& their wives / parents in selected rural \& urban.
7. American Psychiatric Association. (2004). Diagnostic \& statistical manual of mental disorders. 4thed, Washington: American Psychiatric Association. Pp:7986

8. Basavanthappa, B.T. (2003). Nursing Research. 1sted, New Delhi: Jaypee Brothers. Pp:41-65.

9. Becuman, L.T. (1989). Proceeding of the indo - us symposium on alcohol and drug abuse. Bangalore: NIMHANS Publications. Pp:330-355.

10. Bhatia, M.S. (2004). Essential of psychiatry. 4thed, New Delhi: CBS publishers \& Distributors. Pp:8.1 - 8.14

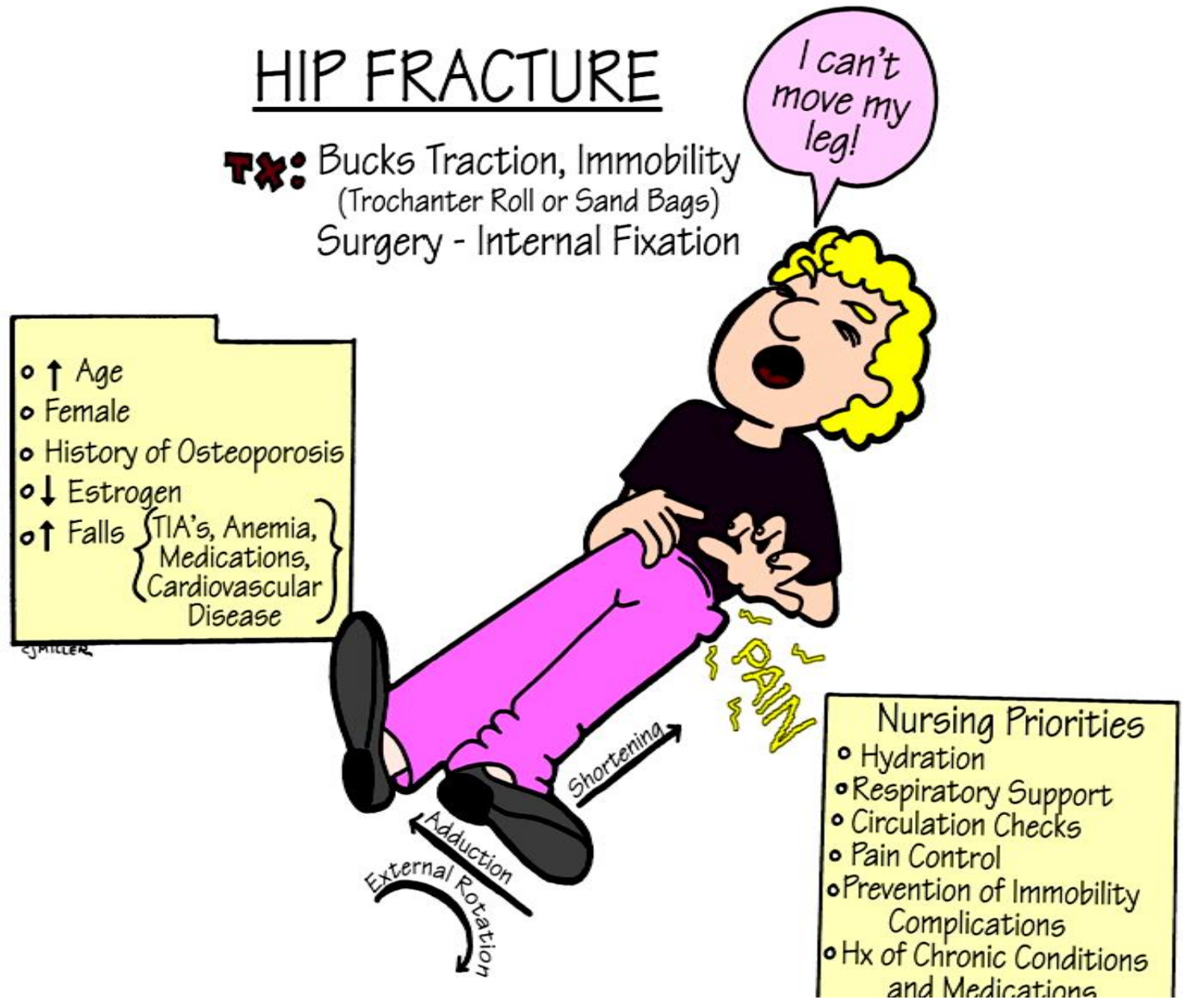

